\title{
Minimalist thoracoscopic resection of thymoma associated with myasthenia gravis
} \author{
Italy, and Tel Aviv, Israel \\ From the Departments of ${ }^{\mathrm{a}}$ Thoracic Surgery, ${ }^{\mathrm{b}}$ Anesthesia and Intensive Care, and ${ }^{\mathrm{c}}$ Neurology, Policlinico Tor Ver- \\ gata University, Rome, Italy; and ${ }^{\mathrm{d}}$ Department of Thoracic Surgery, Assaf Harofeh Medical Center, affiliated \\ with the Sackler Faculty of Medicine, Tel-Aviv University, Tel Aviv, Israel. \\ Disclosures: Authors have nothing to disclose with regard to commercial support. \\ Received for publication Feb 14, 2017; revisions received April 26, 2017; accepted for publication May 29, 2017; \\ available ahead of print June 22, 2017. \\ Address for reprints: Eugenio Pompeo, MD, FETCS, Department of Thoracic Surgery, Policlinico Tor Vergata \\ University, V.le Oxford, 81, Rome 00133, Italy (E-mail: pompeo@med.uniroma2.it). \\ J Thorac Cardiovasc Surg 2017;154:1463-5 \\ $0022-5223 / \$ 36.00$ \\ Copyright $(2017$ by The American Association for Thoracic Surgery \\ http://dx.doi.org/10.1016/j.jtcvs.2017.05.084
}

Eugenio Pompeo, MD, FETCS, ${ }^{\mathrm{a}}$ Mario Dauri, MD, ${ }^{\mathrm{b}}$ Roberto Massa, MD, ${ }^{\mathrm{c}}$ and Michael Peer, MD, ${ }^{\mathrm{d}}$ Rome,
- Video clip is available online.

Video-assisted thoracic surgery (VATS) strategies, including single-incision approaches, have been reported to resect stage I to II thymomas with or without associated myasthenia gravis (MG). ${ }^{1-3}$ In addition, in recent years, nonintubated anesthesia protocols also have been proposed in delicate patient cohorts in an attempt to avoid potential adverse effects of general anesthesia with double-lumen tube intubation, curarization, and mechanical ventilation. $^{4}$

We describe herein a novel ultraminimally invasive, or minimalist, surgical method entailing adoption of uniportal VATS combined with use of regional anesthesia and maintenance of spontaneous ventilation through a laryngeal mask that we selectively employed for resection of MGassociated thymomas.

\section{OPERATIVE TECHNIQUE AND RESULTS}

An epidural catheter was inserted at the T4 to T5 level for thoracic analgesia. Sedation was induced by propofol using target controlled infusion at effect site concentration of 4 to $6 \mu \mathrm{g} / \mathrm{mL}$ and subsequently adjusted by $0.2 \mu \mathrm{g} / \mathrm{mL}$ stepwise increase. Following insertion of a laryngeal mask, spontaneous breathing was maintained through an internal breathing circuit with fresh gas flow of 8 to $10 \mathrm{~L} / \mathrm{min}$ and adequate inspired oxygen fraction to keep blood oxygen saturation $>$ 95\%. Whenever necessary, spontaneous ventilation was assisted to maintain end tidal carbon dioxide level $<60 \mathrm{~mm}$ $\mathrm{Hg}$ and $\mathrm{pH}>7.25$.

Patients were placed in a $30^{\circ}$ semilateral position (Figure 1) and through a single $3-\mathrm{cm}$ incision in the right

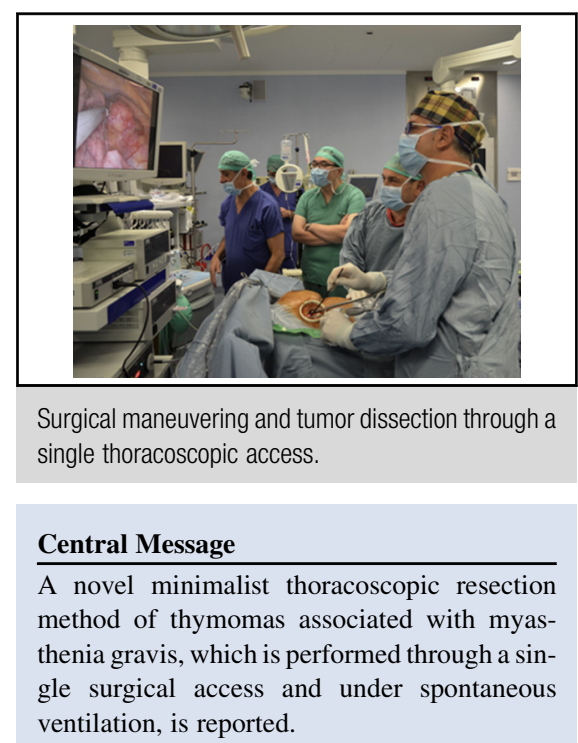

See Editorial Commentary page 1466.

chest along the submammary sulcus, a wound-covering toracoport (Alexis; Apllied Medical, Rancho Santa Margarita, Calif) was inserted. Thymic dissection started inferiorly and proceeded gradually in an upward direction until division of the thymic veins and isolation of the upper horns of the thymus was achieved. Radical removal of the tumor and the entire thymus gland, including perithymic fatty tissue that was found between both phrenic nerves laterally, in the cardiophrenic angles inferiorly, and in the lower cervical region superiorly was accomplished to achieve an intentional extended thymectomy. Opening of the left mediastinal pleura was not intentionally performed.

Blunt surgical dissection was carried out by endoscopic cotton swabs whereas sharp dissection was done using a Harmonic scalpel (Ultracision; Ethicon Endosurgery, Pomezia, Italy). One chest tube was inserted in the anterior mediastinum at the end of the procedure (Video 1 ).

Amongst 3 patients undergoing the procedure, 2 women and 1 man with a mean age of 45 years, Myasthenia Gravis Foundation of America MG stage was 2a in 2 instances and stage $3 \mathrm{a}$ in 1 instance. Preoperatively, all patients were taking pyridostigmine whereas no patients were taking steroids. One patient (stage 3a) underwent immunoglobulin treatment 15 days before surgery. Immediately after the operation, all patients were transferred to a recovery room 


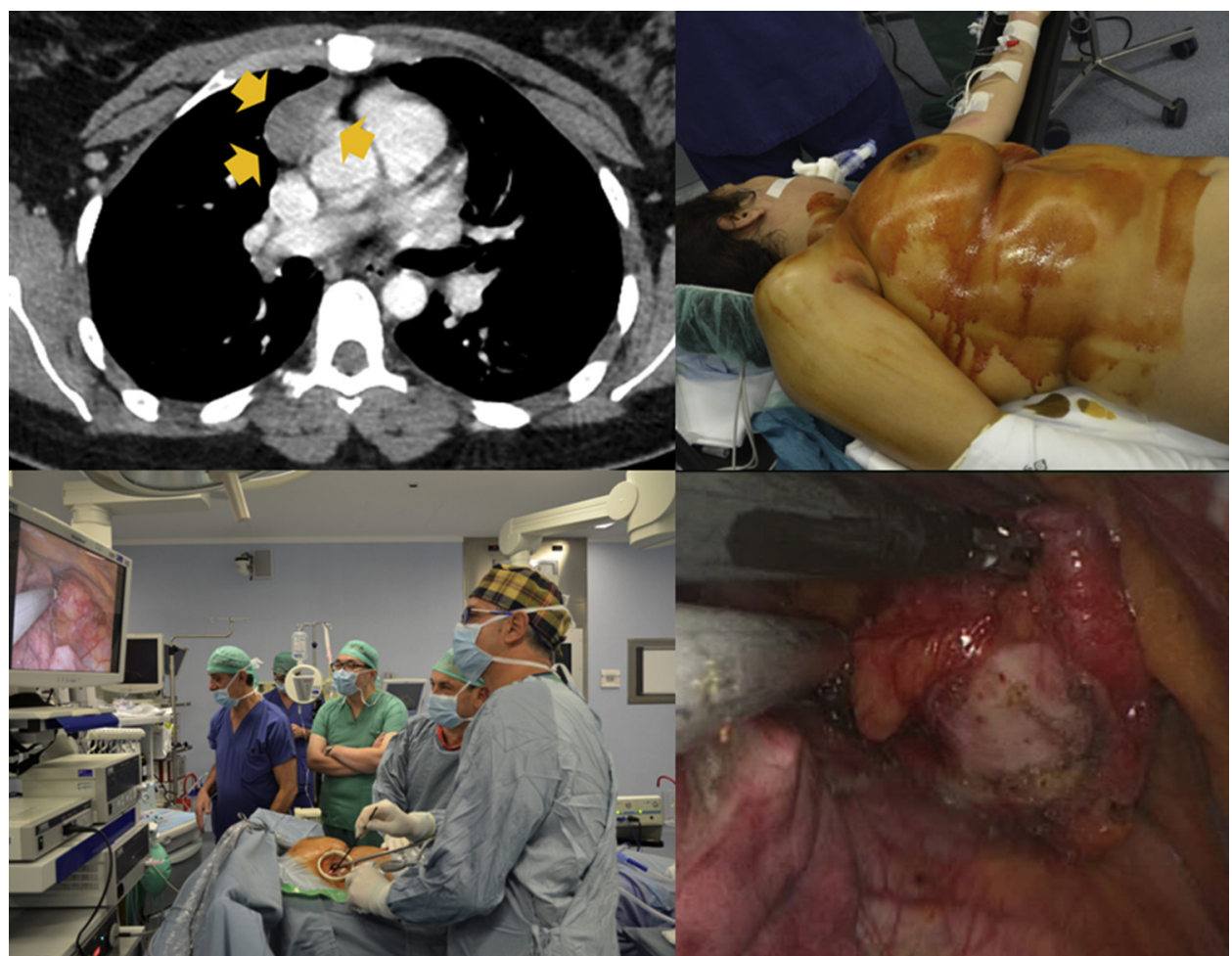

FIGURE 1. Top left, Chest computed tomography scan showing the tumor in the anterior superior mediastinum (arrows). Top right, Patient positioning. Bottom left, Operative setup. Bottom right, Surgical maneuvering and tumor dissection along the pericardial plane.

for a 1-hour observation. Once transferred to the thoracic surgery ward, patients were immediately allowed to start drinking and walking. The postoperative course was uneventful in all instances and mean hospital stay was $1.3 \pm 0.5$ days. The mean size of tumors was $3.5 \pm 1 \mathrm{~cm}$. Histologic examination showed an R0 resection of 2 type A (both Masaoka stage I) and of 1 type AB (Masaoka stage IIa) thymomas. Outcomes of the patients are detailed in Table 1.

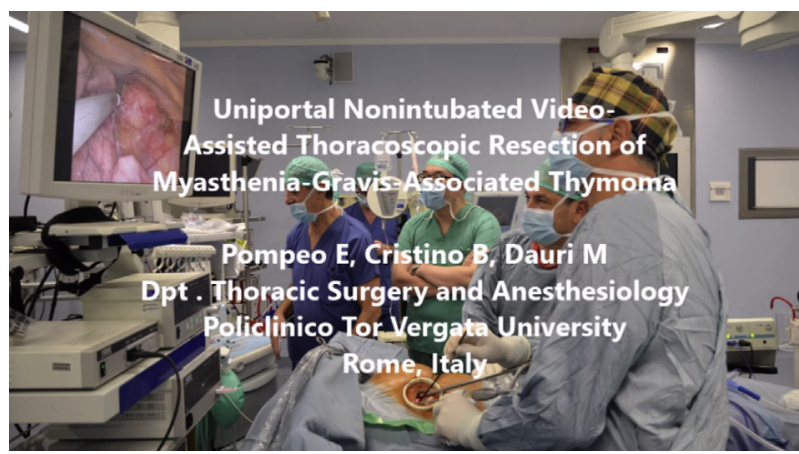

VIDEO 1. The surgical procedure performed by uniportal video-assisted thoracoscopic surgery under spontaneous ventilation. Video available at: http://www.jtcvsonline.org/article/S0022-5223(17)31146-7/addons.

\section{DISCUSSION}

Our evolutionary, minimalist VATS resection method, entailing a combination of uniportal access with nonintubated anesthesia, resulted in excellent perioperative outcomes and short hospital stays.

Adoption of thoracic epidural analgesia with mild sedation and maintenance of spontaneous ventilation through a laryngeal mask resulted in safe perioperative ventilation outcomes and optimal analgesia, which might translate into potential advantages in patients with thymomas and generalized MG, including reduced postoperative morbidity. ${ }^{4}$

Postoperative myasthenic crisis with respiratory failure and requirement of postoperative mechanical ventilation have been respectively reported in $11.4 \%$ and $9.8 \%$ of patients with MG undergoing transsternal thymectomy with endotracheal intubation and mechanical ventilation, respectively. ${ }^{5}$ Maintenance of spontaneous ventilation through a laryngeal mask offered a surgical view that paralleled that achievable by single-lung ventilation and allowed to safely and satisfactorily assist ventilation without the need of conversion to tracheal intubation when both mediastinal pleuras were incidentally or deliberately opened intraoperatively.

Through a right-sided single operative port, visualization of the entire anterior-superior mediastinum up to the lower 
TABLE 1. Operative outcome and follow-up in 3 patients

\begin{tabular}{|c|c|c|c|c|c|c|c|c|c|}
\hline Age (y) & Sex & $\begin{array}{c}\text { Operative } \\
\text { time (min) }\end{array}$ & $\begin{array}{c}\text { Postoperative } \\
\mathrm{PaO}_{2} / \mathrm{Fio}_{2} *\end{array}$ & $\begin{array}{c}\text { Postoperative } \\
\mathrm{PaCO}_{2}(\mathrm{~mm} \mathrm{Hg})^{*}\end{array}$ & $\begin{array}{c}\text { Postoperative } \\
\text { pain (VAS) }\end{array}$ & $\begin{array}{c}\text { Hospital } \\
\text { stay (d) }\end{array}$ & Follow-up (mo) & $\begin{array}{c}\text { Myasthenia } \\
\text { gravis status } \dagger\end{array}$ & $\begin{array}{l}\text { Thymoma } \\
\text { recurrence }\end{array}$ \\
\hline 38 & $F$ & 65 & 242 & 44 & 2 & 2 & 12 & Improved & No \\
\hline 43 & F & 55 & 300 & 39 & 3 & 1 & 8 & Improved & No \\
\hline 55 & M & 60 & 255 & 41 & 1 & 1 & 8 & Unchanged & No \\
\hline
\end{tabular}

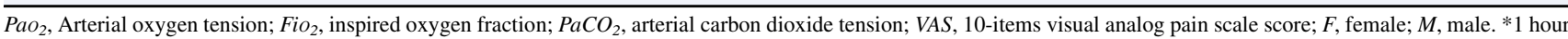
after completion of the surgical procedure. $\dagger$ According to the Myasthenia Gravis Foundation of America posttreatment classification.

cervical area was highly satisfactory without the need of carbon dioxide insufflation. It also offered straightforward access to the junction between the innominate vein and the superior vena cava, which must be dissected free to isolate and divide the thymic veins. Finally, adoption of a nonelectrically activated harmonic scalpel abolished the risk of electrically triggered arrhythmias.

Our data are preliminary and must be considered with caution both from clinical and oncological standpoints due to the lack of comparative results with more standardized surgical approaches. For this reason, we kept inclusion criteria within reasonably safe limits, including a preoperative diagnosis of thymomatous MG with Myasthenia Gravis Foundation of America stage $\leq 3$, body mass index $<30$, and radiologic features suggesting stage I thymoma with maximal diameter $\leq 5 \mathrm{~cm}$.

\section{CONCLUSIONS}

We report on a novel, minimalist VATS method for resection of MG-associated thymoma that holds promise but warrants more detailed investigation with larger samples and longer follow-up to prove its effectiveness.

This study was performed within a jointly signed Inter-Institutional research program between the Tor Vergata University of Rome and the Assaf Harofeh Medical Center of Tel-Aviv.

\section{References}

1. Sakamaki Y, Oda T, Kanazawa G, Shimokawa T, Kido T, Shiono H. Intermediate-term oncologic outcomes after video-assisted thoracoscopic thymectomy for early-stage thymoma. J Thorac Cardiovasc Surg. 2014;148: 1230-7.

2. Wu CY, Heish MJ, Wu CF. Single port mediastinal tumor resection: Taiwan experience. Ann Cardiothorac Surg. 2016;5:107-11.

3. Chao YK, Liu YH, Hsieh MJ, Wu YC, Chen TP, Lu MS. Long-term outcomes afte thoracoscopic resection of stage I and II thymoma: a propensity-matched study. Ann Surg Oncol. 2015;22:1371-6.

4. Tacconi F, Rogliani P, Cristino B, Gilardi F, Palombi L, Pompeo E. Minimalist video-assisted thoracic surgery biopsy of mediastinal tumors. J Thorac Dis. 2016;8:3704-10.

5. Watanabe A, Watanabe T, Obama T, Mawatari T, Ohsawa H, Ichimiya Y. Prognostic factors for myasthenic crisis after transsternal thymectomy in patients with myasthenia gravis. J Thorac Cardiovasc Surg. 2004;127: 868-76. 